http://jmscr.igmpublication.org/home/ ISSN (e)-2347-176x ISSN (p) 2455-0450 crossref DOI: https://dx.doi.org/10.18535/jmscr/v7i8.40

\title{
A one year review of clinical profile and treatment outcomes of neonates admitted to Sick Newborn Care Unit (SNCU) at Regional hospital in Himachal Pradesh draining a rural area
}

\author{
Authors \\ Dr Swati Mahajan ${ }^{1}$, Dr Mohit Bajaj ${ }^{*}$, Dr Ajay Vaid ${ }^{3}$, Dr Amar Thakur ${ }^{4}$ \\ ${ }^{1}$ Medical Officer, General Medicine, Regional Hospital Kullu, HP \\ ${ }^{2,3,4}$ Medical Officer, Pediatrics, Regional Hospital Kullu, HP \\ *Corresponding Author \\ Dr Mohit Bajaj Pediatrician \\ Address: House no. 58/A, ward no. 2, Shamshi, P.O Shamshi, Distt. Kullu (H.P.), India
}

\begin{abstract}
Background: Neonatal period is very important and precious period because most of the preventable morbidities and mortalities occur in this period. In our country, prematurity, infection and perinatal asphyxia are three major causes for neonatal mortality. Special Neonatal Care Units (SNCUs) have been established at district hospitals to combat this challenge.

Methods: This observational retrospective study was planned to determine the clinical profile and outcome of various neonatal admissions at SNCU, Regional Hospital Kullu, a hospital mainly serving the rural population. The data was collected for a time period of one year from 01/08/2018 to 31/07/2019. Detailed information was collected from files and registered onto the preset proformas and results were compiled and evaluated on master chart.
\end{abstract}

Results: A total of 764 neonates were included in this study. Out of them 472(61.7\%) were inborn and $292(38.3 \%)$ were outborn admitted from emergency/OPD or referred from adjoining area. There were 447 males and 317 females with male to female ratio of 1.4:1 and 341(44.7\%) of total admissions were full term. Major indications for admission were neonatal jaundice [379(53.3\%], prematurity [239(31.28\%)] and sepsis [83(10.86\%)]. The range of hospital stay was from 1 day to 15 days with average hospital stay of 1 to3 days. Mortality rate was 3\% during this period and main cause of mortality was RDS and prematurity.

Conclusion: Neonatal period is a very crucial period for development of morbidity and mortality. SNCUs with skilled staff can prevent the worst outcomes by early interventions.

Keywords: SNCU, Neonate, Morbidity, Mortality, Outcome.

\section{Introduction}

Neonatal period is a very crucial time for a neonate as it has to survive on its own in extra uterine life. During this period newborn is highly susceptible to hypothermia, sepsis and birth asphyxia. Globally, neonatal deaths constitute
$44 \%$ of all deaths in less than 5 years age group. ${ }^{[1]}$ In India, neonatal mortality contributes almost two-thirds of the infant deaths and half of the under-five deaths. ${ }^{[2]}$ Current Neonatal Mortality Rate (NMR) in India is $25 / 1000$ live births. ${ }^{[3]}$ Seventy five percent of neonatal deaths occur in 
first week of life. ${ }^{[3]}$ The major causes which contribute to neonatal mortality in developing countries are prematurity, low birth weight, neonatal infections and birth asphyxia. Together they constitute $78 \%$ of all causes. ${ }^{[4]}$ Most of the causes of morbidity and mortality in the neonatal period are preventable by good antenatal care and by early interventions in neonatal period.

Establishment of Special Care Neonatal Units (SNCUs) in rural and urban hospitals can play a critical role in reducing the neonatal morbidity and mortality.

SNCU at District Hospital is expected to provide various services ${ }^{[5]}$ like resuscitation of asphyxiated newborns, management of sick newborns, management of hypothermia, hypoglycaemia, post-natal care, follow-up of high risk newborns, referral and immunization services. These SNCUs are equipped with life saving equipments like radiant warmers, phototherapy units, oxygen concentrators, pulse oximeter and intravenous infusion pumps and highly skilled SNCU staff. Further aim of these SNCUs is to strengthen the skilled staff with nurse to bed ratio of 1:1.2 and doctor to bed ratio of $1: 4{ }^{[6]}$

We conducted this study to study various causes of admission at SNCU Kullu and various neonatal outcomes for a period of one year (2018-2019).

\section{Methods}

This is a hospital data based retrospective study conducted at SNCU Kullu: a hospital, serving rural population mainly. Information regarding epidemiology, clinical presentation, morbidities and outcomes were recorded from patient's files on pre-formed proformas.

Inclusion Criteria: All admitted babies of less than 28 days were included.

\section{Exclusion Criteria}

1) Parents denied for the consent.

2) Babies more than 28 days of age

3) Neonates who were not admitted in SNCU.

Statistical analysis was done by using Microsoft Office Excel.

\section{Results}

SNCU Kullu is a newly established 12 bedded unit ( 4 years old). It is staffed by 3 pediatricians and 6 staff nurses with nurse to bed ratio of $1: 1$ and doctor to bed ratio of 1:2 currently.

A total of 764 newborns were enrolled for this study. 472(61.7\%) babies were inborn and 292 (38.3\%) were outborn. There were 447 males and 317 females with male to female ratio of $1.4: 1$ (Figure-1).

Figure 1: Gender Wise Distribution of Neonates

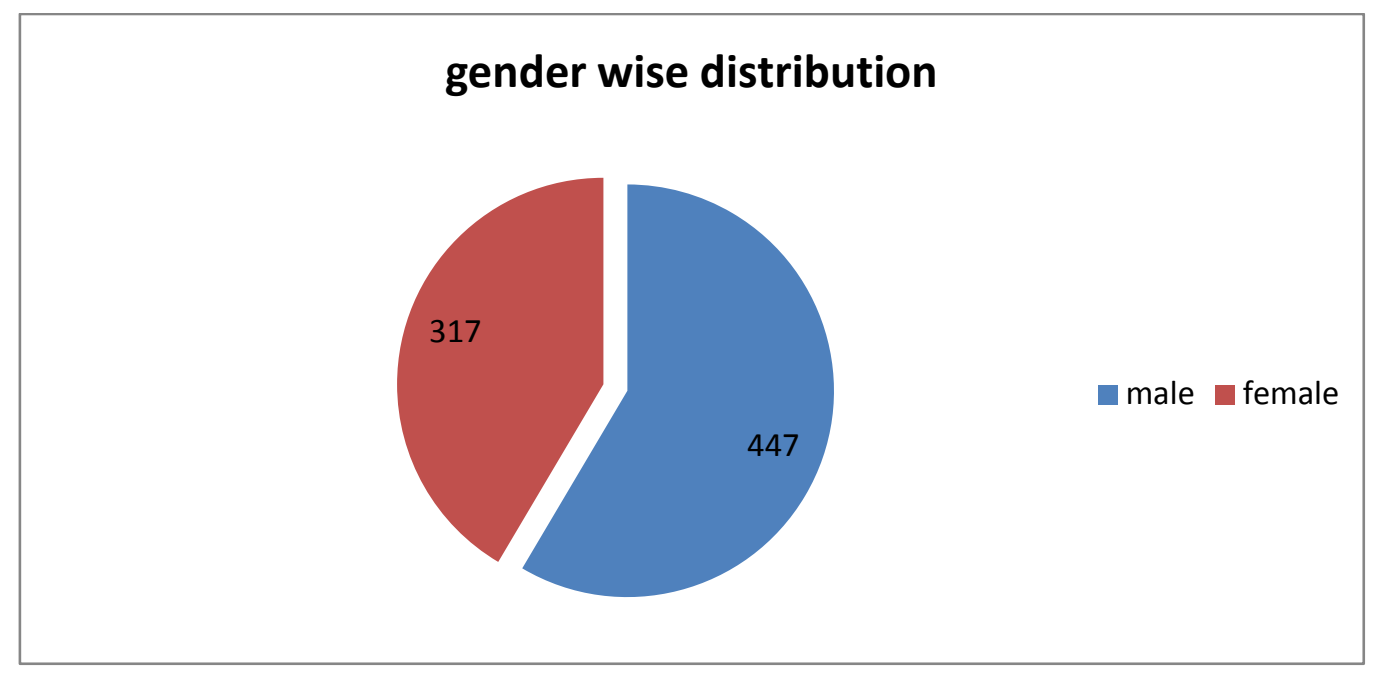

Mode of delivery was spontaneous vaginal 229(30\%) mothers. Majority 525(68.71\%) of the delivery in $535(70 \%)$ and cesarean section in babies were term and rest $(31.29 \%)$ were preterm. 
Figure 2: Gestation age of Neonates

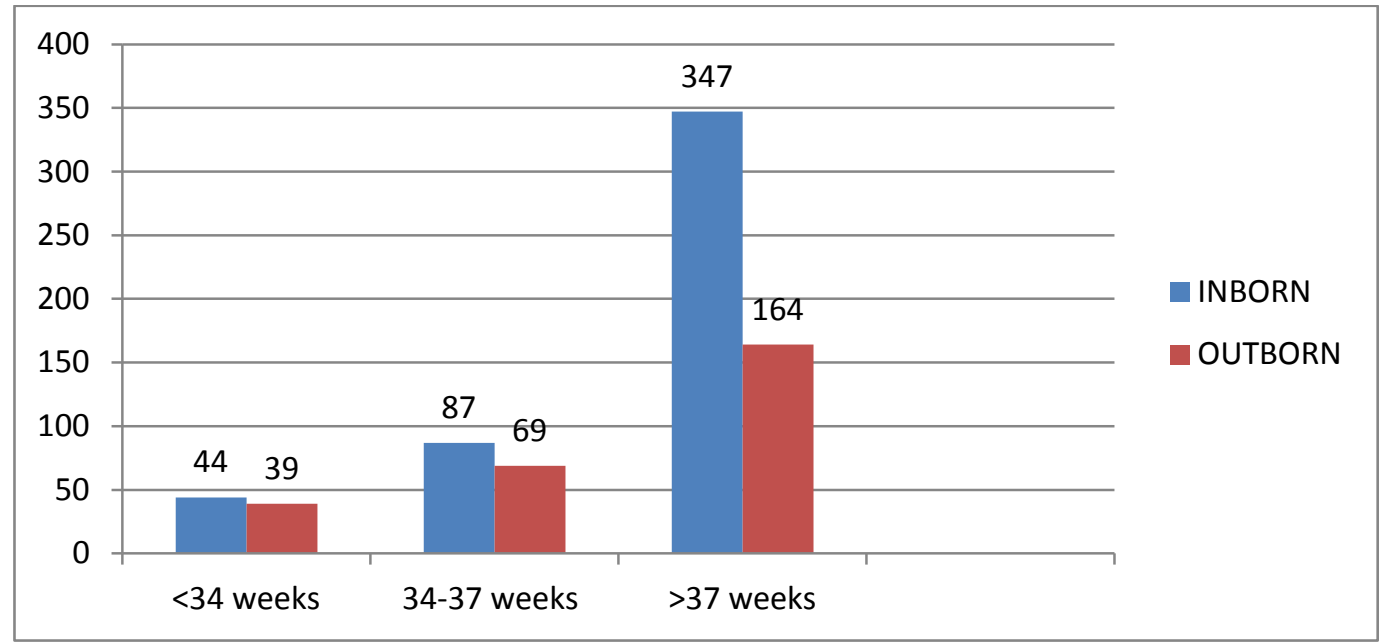

Figure 3: Weight Wise Distribution of Neonates

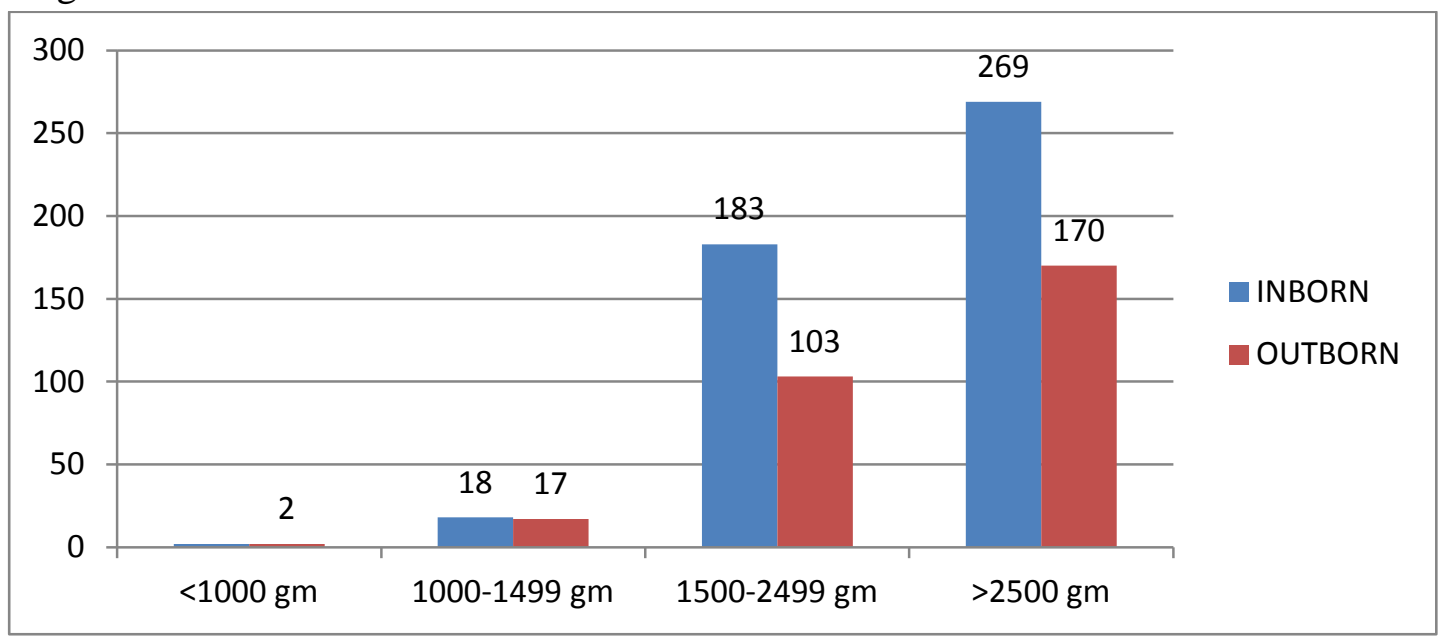

Majority of neonates i.e $439(57.46 \%)$ were having birth weight $>2.5 \mathrm{~kg}$ and $325(42.54 \%)$ were having low birth weight i.e $<2.5 \mathrm{~kg}$.

Figure 4: Morbidity Profile of Neonates at Admission

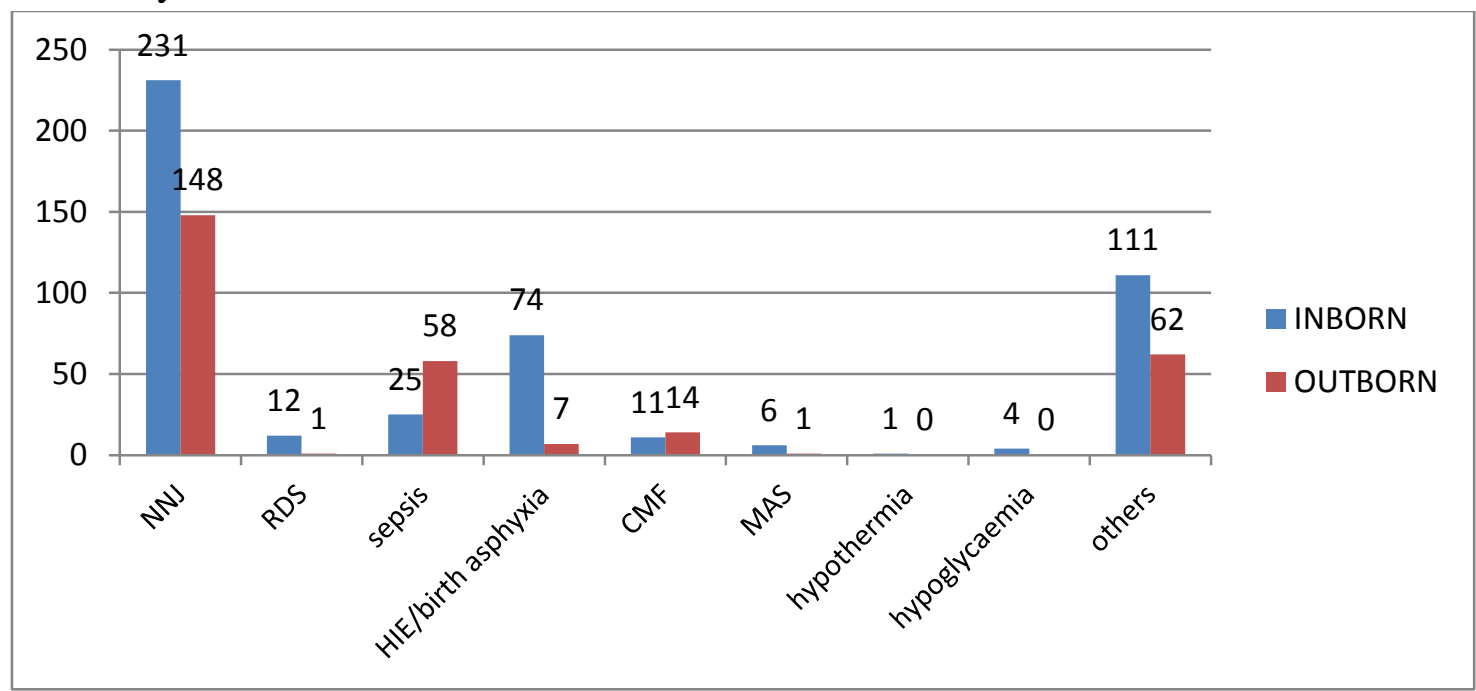

The most common cause of admission was neonatal jaundice [379(53.3\%] in both inborn and outborn neonates. 
Figure 5: Duration of stay at SNCU

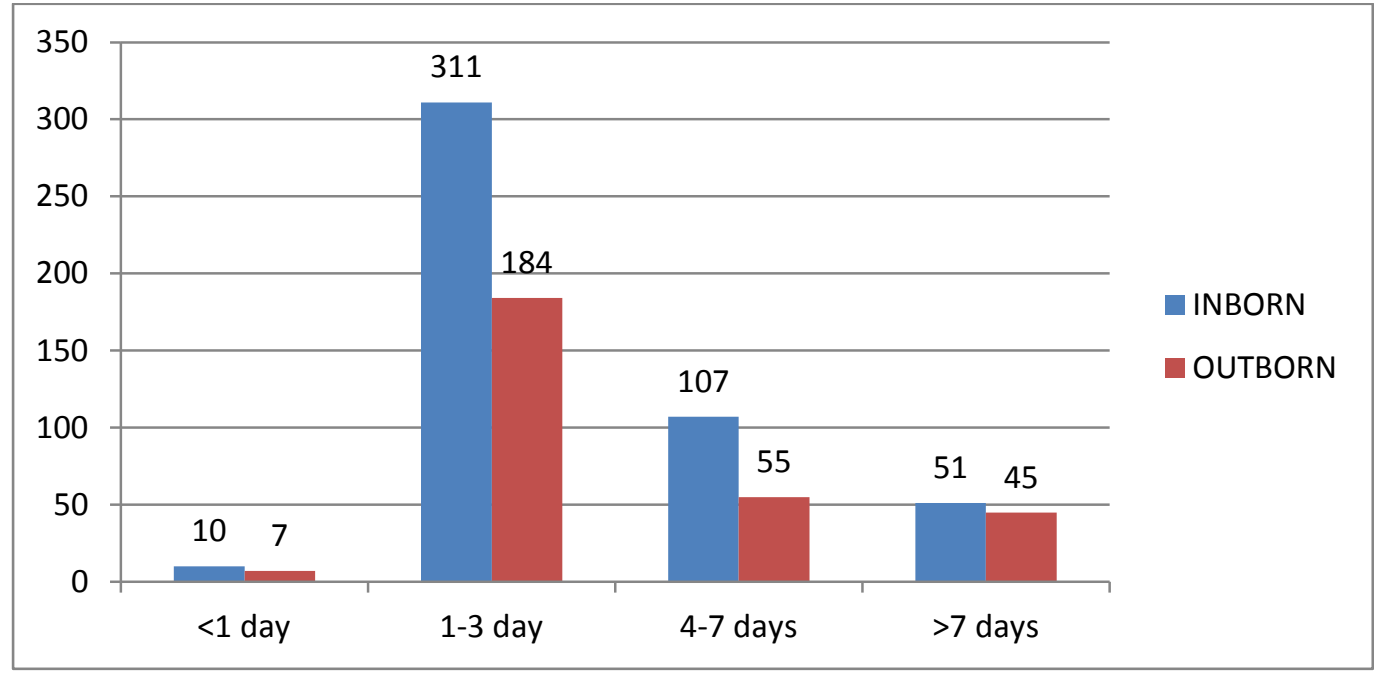

Most common duration of stay in SNCU was 1-3 days in inborn and outborn Average duration of stay in inborn was 4.1 days and 4.4 days in outborn.

Figure 6: Mortality Profile of Neonates

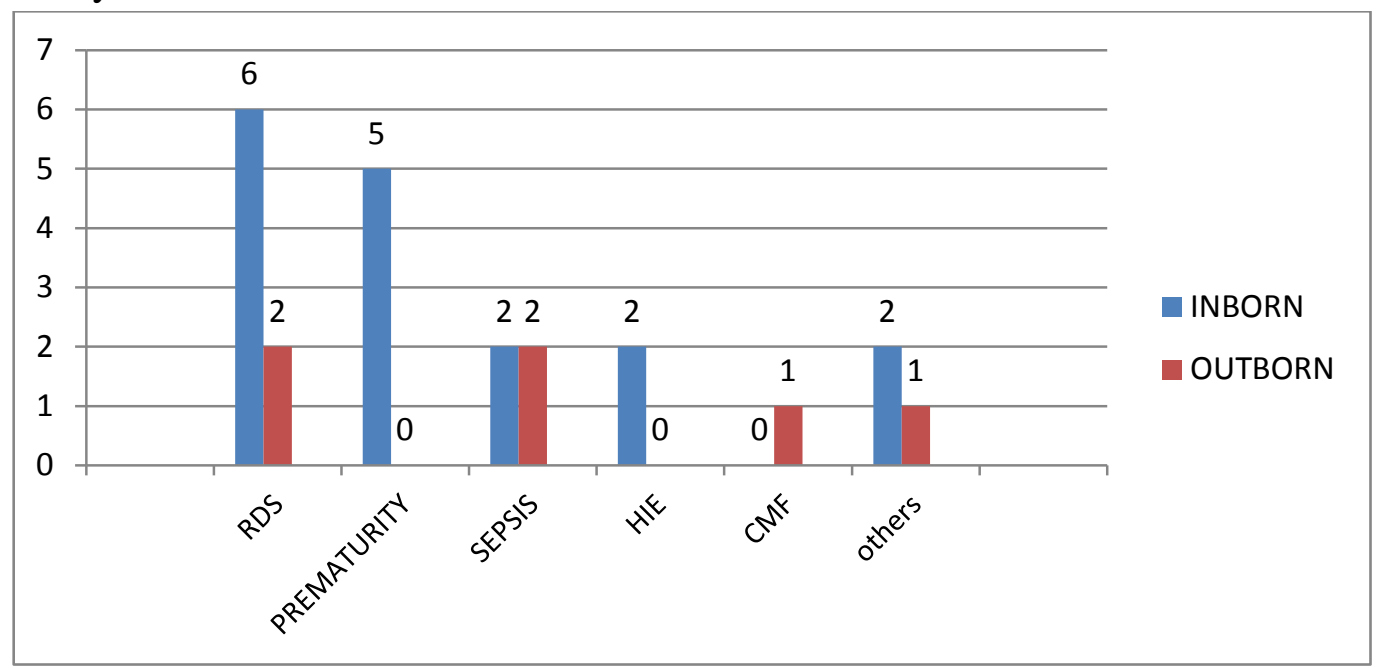

The most common cause of mortality was RDS followed by prematurity in inborn and RDS and sepsis in outborn respectively.

Figure 7: Duration between time of admission and death

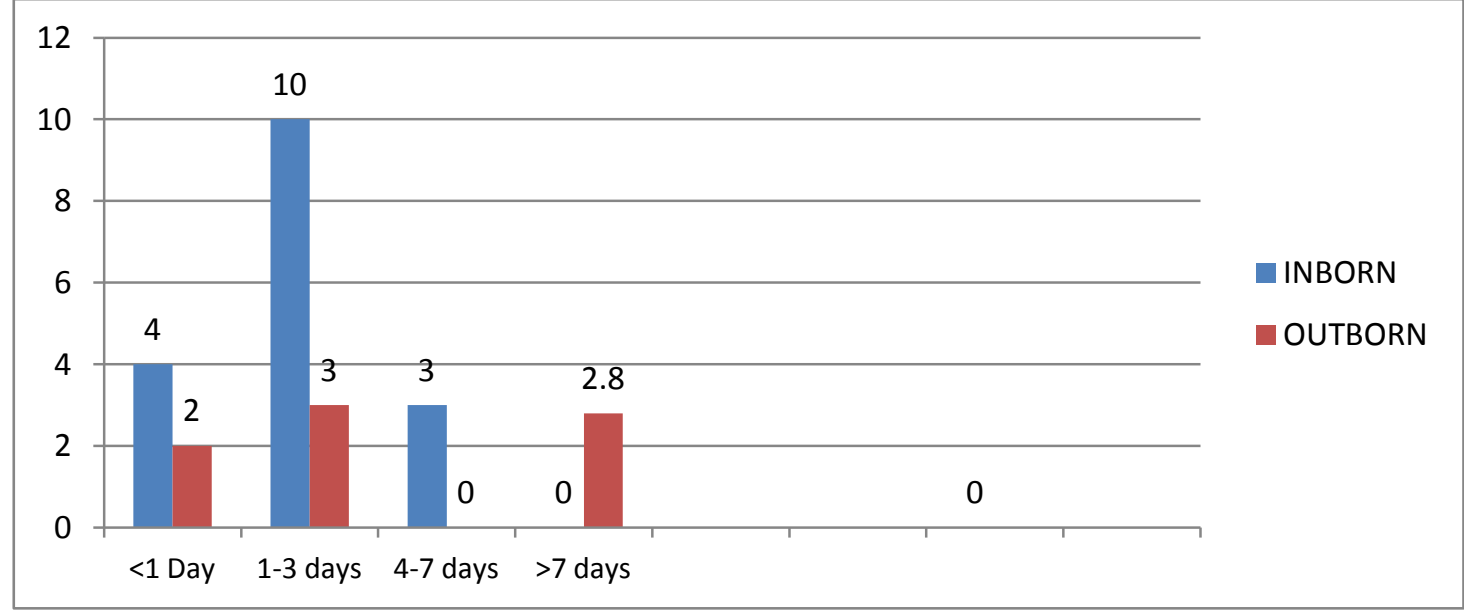


Figure 8: Age of Newborn at Death

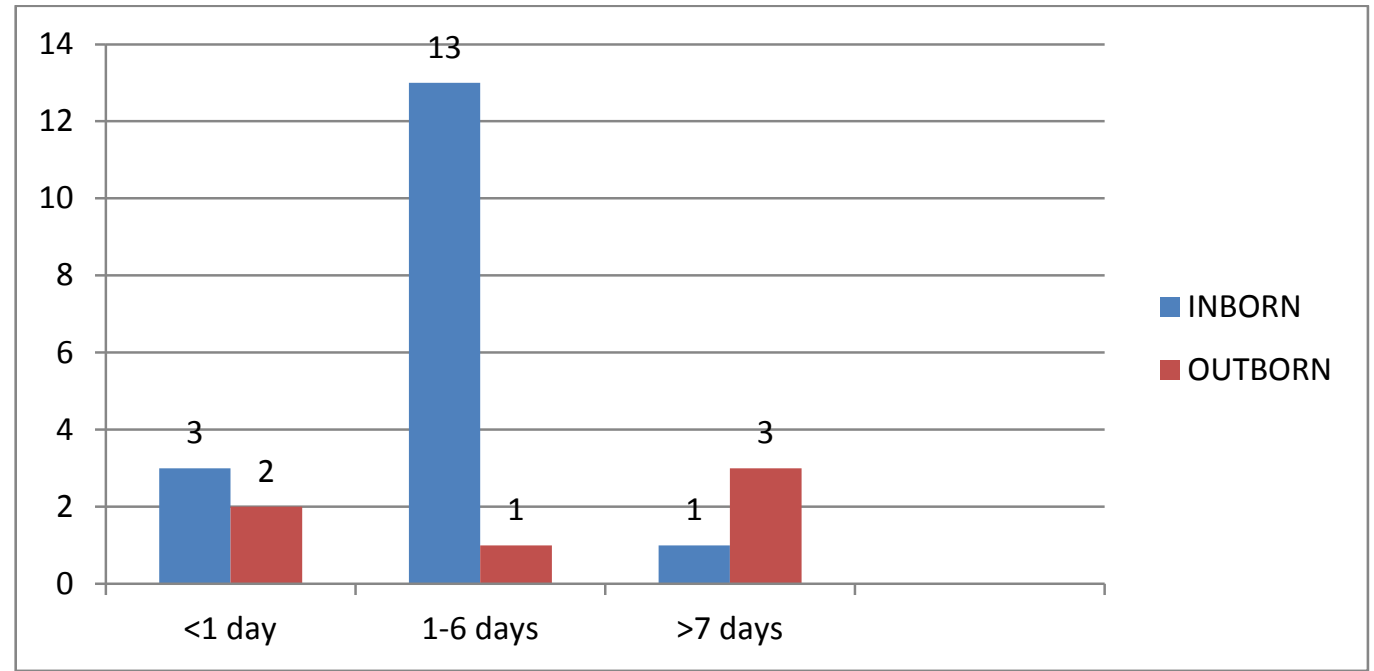

Figure 9: Weight Wise Distribution of Mortality Profile of Neonates

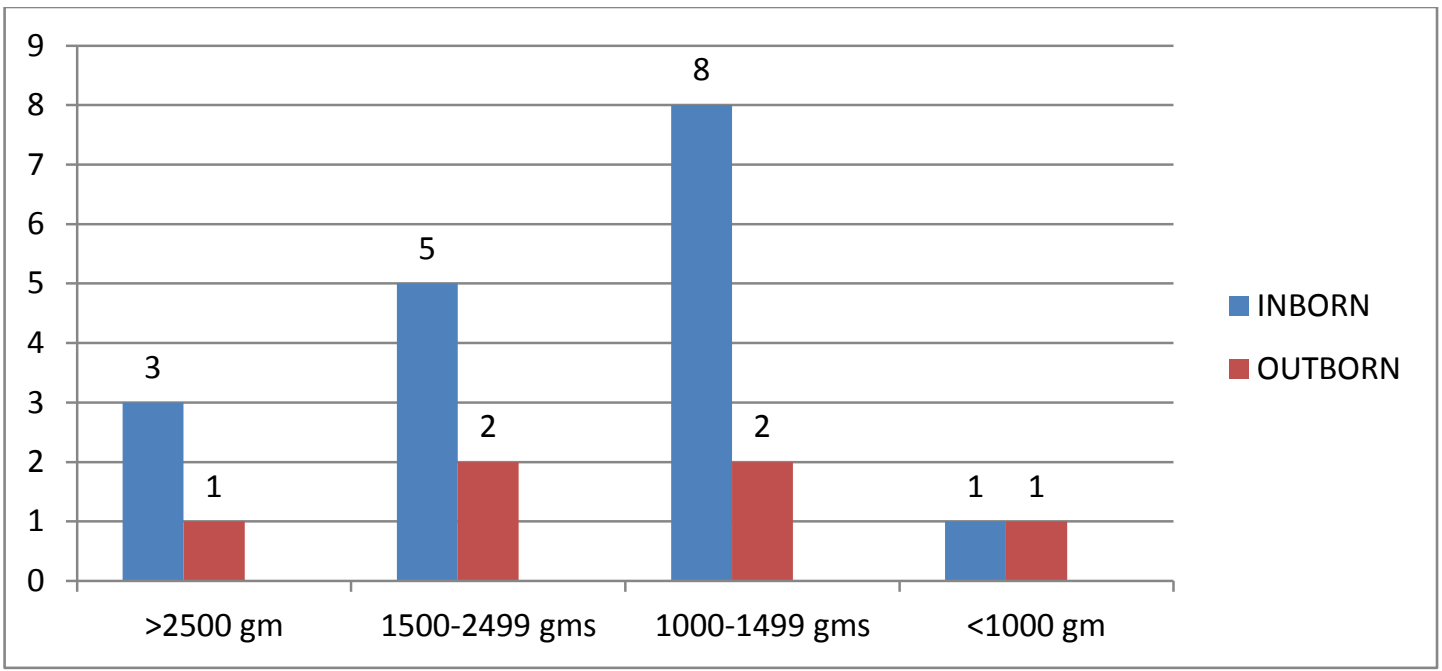

Figure 10: Gestation Wise Distribution of Mortality Profile of Neonates

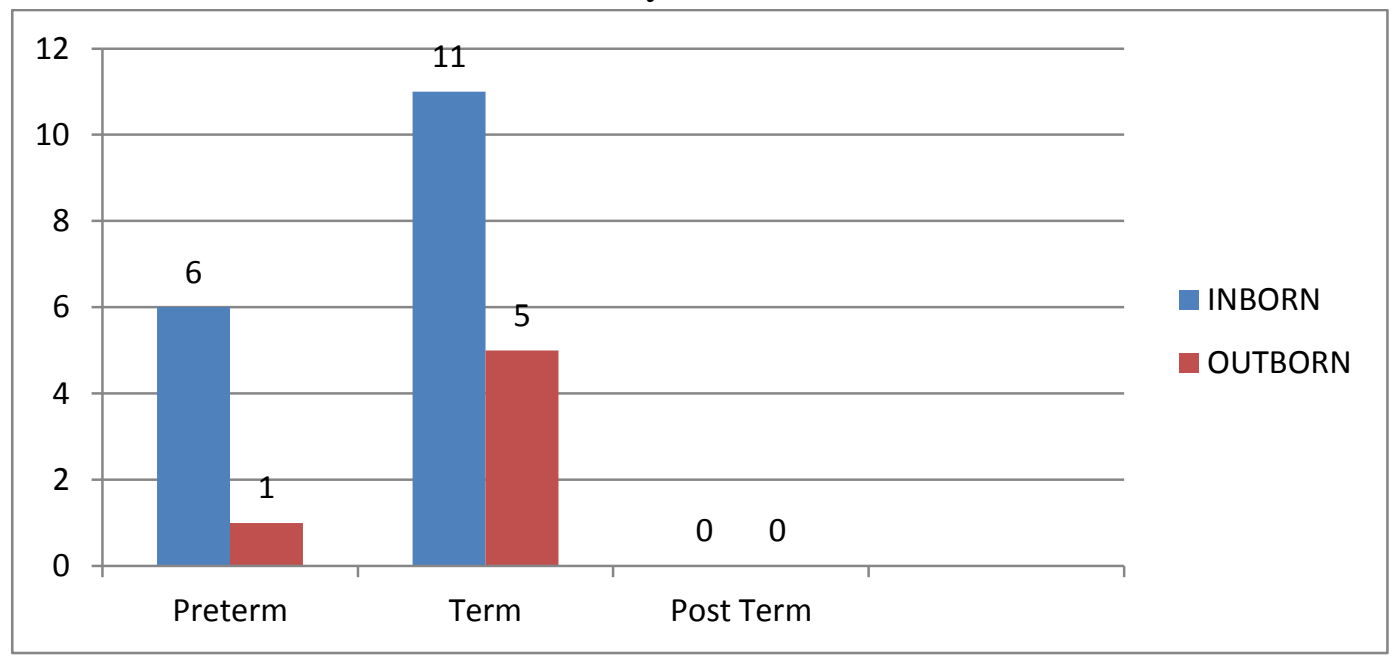

Mortality data shows that leading cause of mortality in newborns was RDS and prematurity in both inborn and outborn. Mortality was highest in weight group of 1000-1499 gms and in term neonates. Most common age at death was between 1- 6 days. 


\section{Discussion}

Establishment of SNCUs and skilled staff is one of the active interventions to reduce neonatal mortality at district level setups. The aim of this study was to identify the patterns of neonatal admissions and factors associated with morbidity and mortality among these neonates. Our results revealed slight male preponderance which is in concordance with studies by Shakya et al and Shreshtha et $\mathrm{al}^{[7,8]}$. This may be because of vulnerability of male neonates and gender preference in the area.

Total no of preterm admitted were $239(31.28 \%$ ) $\%$ out of which 131(17.14\%) were inborn and $108(14.14 \%)$ were outborn which is consistent within the range of $25.8 \%-50.4 \%$ as reported from other studies ${ }^{[9,10]}$. Most of preterm were of gestation between 34-37 weeks.

In our study, we observed no difference in LBW admission rates of inborn and outborn (203 $(43.0 \%) \mathrm{v} / \mathrm{s}$ 122(41.78\%) and this data is comparable with data from other studies done in India $(40 \%) \cdot{ }^{\left[{ }^{9,10]}\right.}$ It also indicates that neonates with low birth weight and pre-term deliveries constitute large number of SNCU admission these days.

In our study, sepsis was found more in outborn babies i.e $58(19.86 \%)$ as compared to inborn ones $25(5.29 \%)$ of total inborn. This indicates unhygienic deliveries either by unskilled person at septic places or baby's exposure to infections during transport or referral.

Neonatal jaundice was leading cause of admission in $231(48.94 \%$ ) inborn neonates and $148(50.68 \%)$ of outborn neonates. The incidence of hyperbillirubinia in our study is $49.64 \%$. this higher incidence is due to the fact that this study was conducted in a tertiary care hospital. A similar high incidence of $35 \%$ was observed in study by Simiyu et $\mathrm{al}^{[11]}$ and $21.97 \%$ in study by Shakya et $\mathrm{al}^{[7]}$.

In our study, we found 25(3.27\%) number of neonates with congenital malformations (CMF) (11 inborn/14 outborn) which is less than data from $\mathrm{WHO}($ about $7 \%$ ). Low incidence may be because of high mortality of newborn with CMF and hence low referral rate.

In our study, we observed an incidence of $81(10.60 \%)$ birth asphyxia admissions. Various other studies reported incidence ranging from $12.7 \%$ to $38.7 \% .^{[19]}$

As our hospital is in a hilly and rural area and main delivery centre, usually mothers reach in advanced stage of labour with complications. This can be the reason for higher rate of above complications amongst inborn. Strengthening of antenatal, intra-partum and post partum care is very important to combat all these complications. In this study, we observed $3.1 \%$ mortality. Mortality rates were found higher $(1.4 \%-27 \%)$ in some studies probably due to more number of preterm babies and sicker neonates. ${ }^{[7,13]}$. The mortality rates depend on many factors like obstetric care, location of referral centre, pattern of referral cases, availability of equipments and skilled man power.

About $26.08 \%$ of deaths were observed within 24 hours of life and $56.52 \%$ deaths occurred within 1-3 days of life. Highest number of deaths (43.47\%) were in inborn group and within 1-3 days of life.

Prematurity and RDS were the most common causes of death. Premature babies having weight in between 1000-1499gms had the highest mortality $(43.47 \%)$.

\section{Conclusion}

Neonatal period is most vulnerable time for development of morbidity and mortality. Neonatal jaundice, prematurity, low birth weight, perinatal asphyxia and sepsis are major causes for SNCU admission and also for morbidity and mortality. SNCU with skilled staff can reduce both morbidity and mortality by early interventions. Neonatal sepsis can be prevented by enforcing strict hand hygiene and aseptic protocols. Low birth weight and prematurity were the significant contributors to mortality. Hence antenatal programs to prevent prematurity and low birth weight babies should be strengthened. 
What is already known?

Prematurity, Low birth weight, Sepsis and birth asphyxia were the common causes of neonatal morbidity and mortality.

\section{What this study adds?}

Neonatal hyper billirubinemia is also an important indication for admission in NICU.

\section{Funding: Nil}

Conflict of interest: None initiated.

\section{References}

1. Levels and Trends in Child Mortality Report 2013. Estimates Developed by the UN Inter-Agency Group for Child Mortality Estimation. New York: UNICEF;2013.

2. Anurekha V, Kumaravel KS, Kumar P,Kumar S. Clinical profile of neonates admitted to a neonatal intensive care unit at a referral hospital in South India. International Journal of Pediatric Research. February 2018;5:2.

3. Shah HD, Shah B, Dave PV, Katariya JB, Vats KP. A step toward healthy newborn: An assessment of 2 years' admission pattern and treatment outcomes of neonates admitted in special newborn care units of Gujarat. Indian $\mathrm{J}$ Community Med[serial online] 2018 [cited 2018 May6];43:14-8.

4. Bassani DG, Kumar R, Awasthi S, Morris SK, Paul VK, Shet A, et al. Causes of neonatal and child mortality in India: a nationally representative mortality survey. Lancet. 2010 Nov 27;376(9755):1853-60. doi: 10.1016/S0140-6736 (10) 61461-4. Epub 2010 Nov 12.

5. Toolkit for setting up Special Care Newborn Units, Stabilisation Units \& Newborn Care Corners"- Multi-centric Home based Intervention Project of the Indian Council of Medical Research [ICMR Annual Report 2005-06].
6. Sharma RK, Khan R, Anjum S. Study to evaluate the functioning of Special Care Newborn Unit (SNCU) established at a District Hospital. IJBR. 2017;08:514-20.

7. Shakya A, Shrestha D, Shakya H, Shah SC, Dhakal AK. Clinical profile and outcome of neonates admitted to the Neonatal Care Unit at a teaching hospital in Lalitpur, Nepal. Journal of Kathmandu Medical College 2014; 3(4) Issue 10:144148.

8. Shrestha SP, Shah AK, Prajapati R, YR Sharma YR. Profile of Neonatal Admission At Chitwan Medical College. Journal of Chitwan Medical College 2013; 3 (6): 13-16.

9. Omoigberale AI, Sadoh WE, Nwaneri DU:A 4 year review of neonatal outcome at the University of Benin Teaching Hospital, Benin City. Niger J Clin Pract 2010;13:321-5.

10. Uganda Bureau of Statistics (UBOS) and Macro International Inc: Uganda Demographic and Health Survey 2006.Calverton, Maryland, USA: UBOS and Macro International Inc; 2007.

11. Simiyu DE. Morbidity and mortality of neonates admitted in general paediatric wards at Kenyatta National Hospital. East Afr Med J. 2003 Dec;80(12): 611-6.

12. Bhatnagar M, Jiwane N. Clinical Profile and Outcome of Babies Admitted to Special Newborn Care Unit (SNCU): Retrospective Observational Study. International Journal of scientific research. 2016; 5:64-6.

\section{Patil Ravindra B, Koppad} Raghavendraswamy, Benakanal Shreeshail. Clinical Profile and Outcome of Babies Admitted to Neonatal Intensive Care Unit (NICU), Mc Gann Teaching Hospital Shivamogga, Karnataka: A Longitudinal Study. Sch. J. App. Med. Sci., 2014; 2 (6G): 3357-3360. 